\title{
Papers
}

\section{Effect of patients' age on management of acute intracranial haematoma: prospective national study}

Philip T Munro, Rik D Smith, Timothy R J Parke

\begin{abstract}
Objective To determine whether the management of head injuries differs between patients aged $\geqslant 65$ years and those $<65$.

Design Prospective observational national study over four years.

Setting 25 Scottish hospitals that admit trauma patients.

Participants 527 trauma patients with extradural or acute subdural haematomas.

Main outcome measures Time to cranial computed tomography in the first hospital attended, rates of transfer to neurosurgical care, rates of neurosurgical intervention, length of time to operation, and mortality in inpatients in the three months after admission.

Results Patients aged $\geqslant 65$ years had lower survival rates than patients $<65$ years. Rates were $15 / 18$ $(83 \%)$ v 165/167 (99\%) for extradural haematoma $(\mathrm{P}=0.007)$ and 61/93 (66\%) v 229/249 (92\%) for acute subdural haematoma $(\mathrm{P}<0.001)$. Older patients were less likely to be transferred to specialist neurosurgical care $(10(56 \%)$ v $142(85 \%)$ for extradural haematoma $(\mathrm{P}=0.005)$ and $56(60 \%) v 192(77 \%)$ for subdural haematoma $(\mathrm{P}=0.004))$. There was no significant difference between age groups in the incidence of neurosurgical interventions in patients who were transferred. Logistic regression analysis showed that age had a significant independent effect on transfer and on survival. Older patients had higher rates of coexisting medical conditions than younger patients, but when severity of injury, initial physiological status at presentation, or previous health were controlled for in a log linear analysis, transfer rates were still lower in older patients than in younger patients $(\mathrm{P}<0.001)$. Conclusions Compared with those aged under 65 years, people aged 65 and over have a worse prognosis after head injury complicated by intracranial haematoma. The decision to transfer such patients to neurosurgical care seems to be biased against older patients.
\end{abstract}

\section{Introduction}

Major trauma, particularly serious head injury, is associated with high mortality in people over 65 years. ${ }^{1}$ It has been suggested that in older patients with a Glasgow coma score of 8 or less, it is more appropriate to err on the side of inactivity and withhold intensive treatment. ${ }^{12}$ However, up to $60 \%$ of older patients with head injuries can make a full recovery ${ }^{3}$ and take up no more resources than younger patients.

In Scotland, age has been shown to be an independent factor in the process of trauma care in elderly patients. ${ }^{5}$ We consider that outcomes are different for older patients with serious but potentially treatable head injuries compared with younger patients with similar injuries. This may be because of differences in management, particularly in rates of transfer to neurosurgical care.

\section{Methods}

We carried out a prospective observational study using data collected by the Scottish Trauma Audit Group, a centrally funded organisation that aims to improve trauma management in Scotland. It collects data on all injured patients who are admitted to hospital for three days or more or who die in hospital. ${ }^{6}$ Data on $98 \%$ of all such patients are collected. Patients who arrive in the accident and emergency department in traumatic cardiorespiratory arrest are excluded unless the period of attempted resuscitation in the department exceeded 15 minutes. Physiological variables are routinely collected on arrival, as well as details of clinical care, surgical interventions, computed tomography, and transfer. Injuries are scored with the 1990 revision of the abbreviated injury scale, and all scoring is checked centrally to ensure accuracy and consistency. ${ }^{7}$ Patient outcome is measured by survival to discharge or a maximum inpatient stay of three months. The audit group also records the occurrence of nine types of pre-existing conditions (cardiovascular, respiratory, disorders of the central nervous system, diabetes, renal, known malignancy, alcoholism, psychiatric, and drug misuse). For the purposes of this analysis, we excluded patients who died in emergency departments.

We compared the outcome and process of care among younger patients (13-64 years) and older patients ( $\geqslant 65$ years) who experienced trauma. In trauma literature 65 years is the conventional age used to define older patients. In Scotland a recent report on their health and wellbeing also used 65 years as the cut-off point to define older people. ${ }^{8}$ During the four year period from 1997 to 2000 in 25 Scottish hospitals the Scottish Trauma Audit Group followed 3051 patients who had incurred serious head injury (score
Accident and
Emergency
Department,
Southern General
Hospital, Glasgow
G51 4TF
Philip T Munro
consultant in accident
and emergency
medicine
Timothy R J Parke
consultant in accident
and emergency
medicine
Scottish Trauma
Audit Group, Royal
Infirmary of
Edinburgh,
Edinburgh
EH3 9YW
Rik D Smith
statistician
Correspondence to:
P T Munro
phil.munro@
sgh.scot.nhs.uk
bmj.com 2002;325:1001 
Table 1 Incidence and type of extradural haematomas or subdural haematomas according to age. Figures are numbers (percentage) of injuries

\begin{tabular}{lccc} 
Haematoma site & AIS code & $<65$ years & $\geqslant 65$ years \\
\hline Extradural haematoma & & & \\
\hline Not further specified & 140630 & $21(13)$ & $6(33)$ \\
\hline Small & 140632 & $91(54)$ & $9(50)$ \\
\hline Bilateral & 140634 & $3(2)$ & $1(6)$ \\
\hline Large & 140636 & $52(31)$ & $2(11)$ \\
\hline Total & & 167 & 18 \\
\hline Subdural haematoma & & & $20(22)$ \\
\hline Not further specified & 140650 & $47(19)$ & $46(49)$ \\
\hline Small & 140652 & $139(56)$ & $7(8)$ \\
\hline Bilateral & 140654 & $16(6)$ & $20(22)$ \\
\hline Large & 140656 & $47(19)$ & 93 \\
\hline Total & & 249 &
\end{tabular}

AIS=abbreviated injury scale haematoma, other serious extracranial injuries, and measures of physiological status (table 3).

There were no significant differences between age groups in the proportions of patients with low Glasgow coma scores, serious extracranial injuries, or large haematomas (table 4). Hypotension or hypoventilation that would have precluded transfer was no more common in older patients than in younger patients (table 4).

Older patients were more likely to have a pre-existing medical condition. We therefore used a log linear model to test whether age and the presence of pre-existing medical conditions had independent effects on transfer to a neurosurgical unit. After we removed non-significant higher order interactions (minimum value $\mathrm{P}=0.2$ ), four significant independent results remained: older patients were more likely than younger patients to have pre-existing medical conditions $\left(\chi^{2}=12.9, \mathrm{df}=1, \mathrm{P}<0.001\right)$ and subdural haematoma $\left(\chi^{2}=18.4, \mathrm{df}=1, \mathrm{P}<0.001\right)$, patients with a preexisting medical condition were more likely to have a subdural haematoma than an extradural haematoma $\left(\chi^{2}=11.1, \mathrm{df}=1, \mathrm{P}<0.001\right)$, and age was independently related to transfer rates (older patients were less likely to be transferred to neurosurgical units after we controlled for type of haematoma and pre-existing medical conditions $\left(\chi^{2}=17.3, \mathrm{df}=1, \mathrm{P}<0.001\right)$ (table 5). Neither the occurrence of pre-existing medical conditions nor the type of intracranial haematoma had additional independent influences on transfer rates $\left(\chi^{2}=0.8, \quad \mathrm{df}=1, \mathrm{P}=0.37\right.$, and $\chi^{2}=3.0, \quad \mathrm{df}=1, \mathrm{P}=0.08$, respectively) (table 5).

\section{Other care measures}

Early diagnosis of brain injuries is particularly important in older patients ${ }^{9}$ so we might expect such patients to undergo computed tomography more quickly than younger patients. As a definite diagnosis was a prerequisite for further care we included in this part of the analysis all patients with a serious head injury (score on abbreviated injury scale $\geqslant 3$ ) who underwent computed tomography $(n=1534$ because start of full data collection system for computed tomography began in August 1998). The median time to computed tomography was 2.3 hours in patients $<65$ years $(\mathrm{n}=1233)$ and 2.7 hours in patients $\geqslant 65$ ( $\mathrm{n}=301$ ) (full computerised tomography data collection began in August 1998; $\mathrm{P}=0.001)$. Overall, 89 (30\%) patients $\geqslant 65$ had not had computed tomography within six hours of arriving in the emergency department compared with 261 (21\%) younger patients $(\mathrm{P}=0.003)$.

Among the subset of 256 patients with an isolated extradural or subdural haematoma who went directly

Table 2 Survival and neurosurgical transfer among patients with extradural haematoma or subdural haematoma. Figures are numbers (percentage) of patients unless stated otherwise

\begin{tabular}{|c|c|c|c|c|c|c|c|c|}
\hline \multirow[b]{2}{*}{ Outcome } & \multicolumn{4}{|c|}{ Extradural haematoma } & \multicolumn{4}{|c|}{ Subdural haematoma } \\
\hline & $\begin{array}{c}<65 \text { years } \\
(n=167)\end{array}$ & $\begin{array}{c}\geqslant 65 \text { years } \\
(n=18)\end{array}$ & $\begin{array}{c}\% \text { difference } \\
(95 \% \mathrm{Cl})\end{array}$ & $P$ value & $\begin{array}{c}<65 \text { years } \\
(n=249)\end{array}$ & $\begin{array}{c}\geqslant 65 \text { years } \\
(n=93)\end{array}$ & $\begin{array}{c}\% \text { difference } \\
(95 \% \mathrm{CI})\end{array}$ & $P$ value \\
\hline Transferred & $142(85)$ & $10(56)$ & $29(6$ to 53$)$ & 0.005 & $191(77)$ & $56(60)$ & 17 (5 to 28$)$ & 0.004 \\
\hline Survived & $165(99)$ & $15(83)$ & NA & 0.007 & $229(92)$ & $61(66)$ & $N A$ & $<0.001$ \\
\hline Survived after transfer & 141 (99) & $8(80)$ & NA & 0.01 & $183(96)$ & $41(73)$ & NA & $<0.001$ \\
\hline Survived without transfer & $24(96)$ & $7(87)$ & NA & 0.43 & $46(79)$ & $20(54)$ & 25 (6 to 44$)$ & 0.01 \\
\hline
\end{tabular}

$N A=$ not applicable because sample percentage $>90 \%$. 
to a neurosurgical unit from the emergency department and had been referred to the neurosurgeons before transfer, 135/218 (62\%) younger patients and 28/38 (74\%) older patients had a documented referral from the emergency department (difference 14\%, 95\% confidence interval $-4 \%$ to $27 \%, \mathrm{P}=0.20$ ). Although documentation of neurosurgical referral from the emergency department was incomplete, we found no evidence of age bias.

Of the patients with an isolated extradural haematoma or subdural haematoma, 171 (41\%) younger patients and $44(40 \%)$ older patients had a documented referral from the emergency department (difference $1 \%,-9 \%$ to $11 \%, \mathrm{P}=0.91$ ). Of those with documented neurosurgical referral, 135 (80\%) younger patients and $28(64 \%)$ older patients were transferred directly to a neurosurgical unit (difference $16 \%, 1 \%$ to $32 \%, \mathrm{P}=0.029)$. This suggests that older patients were as likely to be referred from the emergency department as younger patients but that they were subsequently less likely to be transferred to the neurosurgical unit.

Of the patients with extradural haematoma or subdural haematoma who were transferred, we found no significant differences related to age in the proportion of patients who underwent neurosurgery (173/333 (52\%) patients $<65$ v 26/66 (39\%) patients $\geqslant 65$; difference $27 \%,-0.4 \%$ to $26 \% ; \mathrm{P}=0.08$ ). Overall, $20 / 26$ $(77 \%)$ older patients who underwent neurosurgery survived (2/3 with extradural haematoma, 18/23 with subdural haematoma).

Prompt neurosurgical intervention in elderly patients is essential. For patients with extradural haematoma or subdural haematoma we found no evidence that older patients were operated on sooner after admission than younger patients: 146/173 (84\%) patients $<65$ years were operated on within 24 hours of admission compared with 19/26 (73\%) patients $\geqslant 65$ (difference $11 \%,-7 \%$ to $29 \% ; \mathrm{P}=0.17$ ). Among patients with extradural haematoma or subdural haematoma who were transferred to a neurosurgical unit, the median length of admission in older patients was longer than that in younger patients (26 days $v 9$ days, $\mathrm{P}=0.007$, and 17 days $v 13$ days, $\mathrm{P}=0.049$, respectively).

\section{Discussion}

The results of our multicentre four year study support those of previous research that show that older patients with serious head injuries have poorer outcomes compared with younger patients with similar injuries. Older
Table 3 Results of logistic regression on factors affecting survival and transfer to neurosurgical care among patients with extradural haematoma or subdural haematoma

\begin{tabular}{|c|c|c|}
\hline Explanatory variables* & $\operatorname{Exp}(B) \dagger(95 \%$ Cl) & $P$ value \\
\hline \multicolumn{3}{|l|}{ Dependent variable—-survival } \\
\hline Age & 0.92 (0.89 to 0.94$)$ & $<0.001$ \\
\hline Respiratory rate & 119.9 (8.5 to 1688$)$ & $<0.001$ \\
\hline Glasgow coma scale group & & $<0.001$ \\
\hline Glasgow coma score 3-8 & 0.09 (0.04 to 0.21$)$ & \\
\hline Glasgow coma score 9-12 & 0.83 (0.83 to 0.26$)$ & \\
\hline Size of haematoma: & & $<0.001$ \\
\hline Not further specified & $9.90(2.83$ to 34.6$)$ & \\
\hline Small & $6.01(2.33$ to 15.5$)$ & \\
\hline Bilateral & $2.13(0.52$ to 8.76$)$ & \\
\hline Neurosurgical transfer & 4.27 (1.77 to 10.3$)$ & $<0.001$ \\
\hline \multicolumn{3}{|l|}{ Log odds constant -3.58} \\
\hline \multicolumn{3}{|l|}{ Not in final model: } \\
\hline Type of haematoma & $0.33(0.10$ to 1.11$)$ & 0.06 \\
\hline Pre-existing medical conditions & 0.91 (0.42 to 1.97$)$ & 0.80 \\
\hline Serious extracranial injuries & $0.39(0.13$ to 1.11$)$ & 0.08 \\
\hline Systolic blood pressure & $2.44(0.47$ to 12.7$)$ & 0.29 \\
\hline Goodness of fit of final model & & $\chi^{2}=3.65, \mathrm{df}=8,0.89$ \\
\hline \multicolumn{3}{|c|}{ Dependent variable-neurological transfer } \\
\hline Age & 0.96 (0.95 to 0.97$)$ & $<0.001$ \\
\hline Serious extracranial injuries & 0.23 (0.12 to 0.42$)$ & $<0.001$ \\
\hline Size of haematoma: & & $<0.001$ \\
\hline Not further specified & $0.79(0.35$ to 1.79$)$ & \\
\hline Small & $0.31(0.16$ to 0.60$)$ & \\
\hline Bilateral & 0.92 (0.28 to 3.07$)$ & \\
\hline Respiratory rate & $36.2(2.82$ to 464$)$ & $<0.001$ \\
\hline Glasgow coma scale group & & 0.01 \\
\hline Glasgow coma score 3-8 & 1.99 (1.11 to 3.55$)$ & \\
\hline Glasgow coma score 9-12 & 2.16 (1.13 to 4.12$)$ & \\
\hline \multicolumn{3}{|l|}{ Log odds constant -3.39} \\
\hline \multicolumn{3}{|l|}{ Not included in final model: } \\
\hline Type of haematoma & 1.00 (0.59 to 1.68$)$ & 0.99 \\
\hline Pre-existing medical conditions & 0.97 (0.60 to 1.57$)$ & 0.90 \\
\hline Systolic blood pressure & $1.94(0.42$ to 9.05$)$ & 0.39 \\
\hline Goodness of fit of final model & & $\chi^{2}=4.63, d f=8,0.80$ \\
\hline
\end{tabular}

*Variables are listed in order they entered forward stepwise selection process. Age was entered as continuous variable, respiratory rate was categorised as 1 (values below 10) and 2 (10 or more); Glasgow coma scale group as 1 (Glasgow coma score 3-8), 2 (Glasgow coma score 9-12) and 3 (Glasgow coma score 13-15); haematoma size as 1 (not further specified), 2 (small), 3 (bilateral) and 4 (large); neurosurgical transfer as 0 (no transfer) and 1 (transferred); type of haematoma as 1 (extradural haematoma) and 2 (subdural haematoma); systolic blood pressure as $1(<90 \mathrm{~mm} \mathrm{Hg})$ and $2(\geqslant 90 \mathrm{~mm} \mathrm{Hg}$ ); serious extracranial injuries as score on abbreviated injury scale $\geqslant 3$; and pre-existing medical conditions as 0 (absent) and 1 (present).

†Factor by which odds change when independent variable increases by one unit; values $>1$ indicate that odds increase as explanatory variable increases and values $<1$ indicate that odds decrease as explanatory variable increases.

patients were also less likely to be transferred to specialist neurosurgical care, although there was no significant difference in their subsequent rates of neurosurgery. Age was a more important influence on neurosurgical transference than other concomitant factors, such as size of haematoma, the incidence of

Table 4 Features of patients with extradural haematoma or subdural haematoma. Figures are numbers (percentage) unless stated otherwise

\begin{tabular}{|c|c|c|c|c|c|c|}
\hline \multirow[b]{2}{*}{ Characteristics } & \multicolumn{3}{|c|}{ Extradural haematoma } & \multicolumn{3}{|c|}{ Subdural haematoma } \\
\hline & $<65(n=167)$ & $\geqslant 65(n=18)$ & $P$ value & $<65(n=249)$ & $\geqslant 65(n=93)$ & $P$ value \\
\hline Large haematomas (where size was specified) & $52(36)$ & $2(18)$ & 0.33 & $47(25)$ & $20(30)$ & 0.42 \\
\hline Serious extracranial injury (score on AIS $\geqslant 3$ ) & $16(10)$ & 0 & 0.37 & $40(16)$ & $14(15)$ & 0.87 \\
\hline Median Glasgow coma score & 14 & 13.5 & 0.12 & 13 & 13 & 0.44 \\
\hline Glasgow coma score $\leqslant 8$ & $21(13)$ & $4(22)$ & 0.34 & $78(31)$ & $23(25)$ & 0.47 \\
\hline Median systolic blood pressure $(\mathrm{mm} \mathrm{Hg})$ & 138 & 139 & 0.36 & 140 & 155 & $<0.001$ \\
\hline Median respiratory rate (breaths/min) & 18 & 18 & 0.51 & 18 & 20 & 0.019 \\
\hline Pre-existing medical conditions & $43(28)$ & $9(53)$ & 0.049 & $102(44)$ & $57(63)$ & 0.003 \\
\hline
\end{tabular}

AIS=abbreviated injury scale. 
Table 5 Influence of age on transfer to neurosurgical facilities for four different groups of patients. Figures are numbers (percentage) of patients transferred

\begin{tabular}{|c|c|c|}
\hline & $<65$ years & $\geqslant 65$ years \\
\hline \multicolumn{3}{|c|}{ No pre-existing medical conditions: } \\
\hline Extradural haematoma & $112(84)$ & $8(50)$ \\
\hline Subdural haematoma & $129(80)$ & $34(68)$ \\
\hline \multicolumn{3}{|c|}{ One or more pre-existing medical conditions: } \\
\hline Extradural haematoma & $43(88)$ & $9(67)$ \\
\hline Subdural haematoma & $102(74)$ & $57(56)$ \\
\hline
\end{tabular}

serious extracranial injuries, and measures of physiological condition on arrival at hospital (including level of consciousness). Although older patients were more likely to have pre-existing medical conditions, significant differences in transfer rates related to age were still seen after we had controlled for these conditions. Age has previously been shown to influence independently the treatment of patients with blunt trauma in Scotland. ${ }^{5}$ We conclude that age also seems to have an independent adverse influence on decisions about neurosurgical transfer.

\section{Outcomes and process of care}

Previous studies of outcomes of head injury in elderly patients have been limited by small numbers, inconsistency of inclusion criteria, or restriction to a single neurosurgical unit or rehabilitation centre. ${ }^{10-13}$ Most studies, however, have shown significantly worse outcomes in older patients with head trauma, especially those with a pre-operative Glasgow coma score $\leqslant 8 \cdot{ }^{12-15}$ On this basis, opinion leaders have argued that doctors dealing with older patients with head injuries should "err on the side of inactivity." Indeed, a previous study of over 60 patients with fatal head injuries showed that $71 \%$ of those under 70 years old were transferred for specialist neurosurgical care compared with only $22 \%$ of those over $70 .^{916} 17$

In common with the results of these studies, we found that older patients were more likely to die from their head injuries. Despite this, overall rates of survival among older patients with extradural haematoma or subdural haematoma were not insubstantial $(83 \%$ and $66 \%$, respectively). Although we do not have data that show the subsequent functional recovery of older patients with head injuries, specialist rehabilitation centres have reported home discharge rates of up to $46 \%$ in patients aged over 65 with severe closed head injury (compared with $82 \%$ of younger patients). ${ }^{18}$

Previous studies have also emphasised that intracranial haematomas are more common and larger in older patients than in younger patients. ${ }^{11}$ Good outcomes from surgery in these patients rely on intervention before coma or pupillary dilation occurs. $^{913}$ Rapid identification and surgical decompression of haematomas may be the most important aspect of treatment in older patients. A more aggressive approach to performing computed tomography is therefore indicated. ${ }^{10} 19$ Early computed tomography is particularly important in older patients because haematomas often present with atypical histories and often are not associated with focal signs. ${ }^{20}$ In our study, patients aged $\geqslant 65$ years waited longer for computed tomography and did not receive a more rapid neurosurgical intervention than younger patients.

\section{What is already known on this topic}

Older patients with acute intracranial haematomas have significantly higher mortality and poorer functional outcome than younger patients with similar injuries

Intracranial haematomas are larger and more common in older patients with head injury than in younger patients

Early diagnosis and surgical intervention for operable lesions is a crucial factor in determining patients' outcomes

\section{What this study adds}

Older patients with acute intracranial haematomas were less likely to be transferred for specialist neurosurgical care than younger patients with similar severities of injuries, extracranial injuries, and physiological status at presentation

Significant differences in transfer rates related to age were still seen after pre-existing medical conditions were controlled for

\section{Conclusions}

Our study shows clear differences between age groups in the process of care and rates of specialist intervention in patients with head injuries. It is unclear to what extent these differences contribute to outcome in these patients or how many had valid clinical reasons for non-intervention. It is possible, however, that doctors' concerns over functional outcomes and survival rates in past studies may have produced a degree of scepticism over the worth of treating older patients with head injuries.

We thank the Scottish Trauma Audit Group, in particular Diana Beard and Jenny Henry, as well as the medical and nursing staff of the contributing hospitals.

Contributors: PTM and TRJP designed and wrote the paper. RDS provided statistical advice, analysed the data, and assisted in revision of the manuscript. PTM is the guarantor.

Funding: None.

Competing interests: None declared.

1 Pentland B, Jones PA, Roy CW, Miller J. Head injury in the elderly. Age Ageing 1986;15:193-202.

2 Maurice-Williams RS. Head injuries in the elderly. $\mathrm{Br} J$ Neurosurg 1999;13:5-8.

3 Van Aalst JA, Morris JA, Yates HK, Miller RA, Bass SM. Severely injured geriatric patients return to independent living: a study of factors influencing function and independence. J Trauma 1991;31:1096-102.

4 Saywell RM, Woods JR, Rappaport SA, Allen TL. The value of age and severity as predictors of costs in geriatric head trauma patients. J Am Geriatr Soc 1989;37:625-30.

5 Grant PT, Henry JM, McNaughton GW. The management of elderly blunt trauma victims in Scotland: evidence of ageism? Injury 2000;31:519-28.

6 Beard D, Henry JM, Grant PT. National audit of the management of injured patients in 20 Scottish hospitals. Health Bull Edinb 2000;58:11826.

7 American Association for Automotive Medicine. The abbreviated injury scale 1990 revision. Illinois: American Association for Automotive Medicine, 1990.

8 Wood R, Bain M. The health and well-being of older people in Scotland.Insights from national data. Edinburgh: Information and Statistics Division, Common Services Agency for NHS Scotland, 2001.

9 Gentleman D, Jennett B, MacMillan R. Death in hospital after head injury without transfer to a neurosurgical unit: who, when and why? Injury 1992;23:471-4.

10 Rozelle CJ, Wofford JL, Branch CL. Predictors of mortality in older patients with subdural hematoma. J Am Geriatr Soc 1995;43:240-4. 
11 Howard MA, Gross AS, Dacey RG, Winn HR. Acute subdural hematomas: an age-dependent clinical entity. J Neurosurg 1989;71:85863.

12 Amacher AL, Bybee DE. Toleration of head injury by the elderly. Neurosurgery 1987;20:954-8.

13 Jamjoom A, Nelson R, Stranjalis G, Wood S, Chissell H, Kane N, et al. Outcome following surgical evacuation of traumatic intracranial haematomas in the elderly. Br J Neurosurg 1992:6:27-32.

14 Bullock R, Teasdale G. Head injuries. In: Skinner D, Driscoll P, Earlam R, eds. ABC of major trauma. 2nd ed. London: BMJ Publishing, 1996:25-31.

15 Fenelli FC, Jonsson J, Champion HR, Morelli S, Fouty WJ. A case contro study for major trauma in geriatric patients. J Trauma 1989;29:541-8.

16 Jennet B. Prognosis of patients with severe head injury. Neurosurgery $1979 ; 4: 283-9$.
17 Mendelow AD. Head injury. In: Walton J, ed. Brain's diseases of the nervous system. 10th ed. Oxford: OUP, 1993:192-4

18 Davis CS, Acton P. Treatment of the elderly brain-injured patient: experience in a traumatic brain injury unit. J Am Geriatr Soc 1988;36:225-9.

19 Seelig JM, Becker DP, Miller JD, Greenberg RP, Ward JD, Choi SC. Traumatic acute subdural hematoma; major mortality reduction in comatose patients treated within four hours. NEngl J Med 1981;304:1511-8.

20 Brown G, Warren M, Williams JE, Adam EJ, Coles JA. Cranial computed tomography of elderly patients: an evaluation of its use in acute neurosurgical presentations. Age Ageing 1993;22:240-3.

(Accepted 6June 2002) 